\title{
Weitere Vorschläge und Anleitungen zur Anlegung von bacteriologischen Museen.
}

\author{
Von \\ Franz Král \\ in Prag.
}

Fine bacteriologische Sammlung von Dauerpräparaten, welche aus den in dieser Zeitschrift ${ }^{1}$ beschriebenen Dosen- und Plattenculturen auf durchsichtigen und undurchsichtigen Nährböden besteht, lässt noch eine Frgänzung durch conservirte Stich- und Strichculturen event. Cultureu in Hüssigen Nährmedien als wünschenswerth erscheinen.

Die Herstellung soleher Dauerpräparate ist mit keinen besonderen Schwierigkeiten verbunden and mit Hülfe des vielfach geübten Zuschmelzens der Reagensröhrchen leicht $z u$ erzielen. Wie derartige Cultureu anzufertigen und zu versehliessen sind, um den Anforderungen an ein Dauerpräparat müglichst zu entsprechen, soll in den nachfolgenden Zeilen in Kürze mitgetheilt werden.

Man lässt runde Reagensröhrchen mit angeschmolzenem Glasfuss, wie Fig. 1 (a. S. 500) zeigt, verfertigen, welche ungefähr 17 bis 19 ram äusseren Durchmesser und eine Gesammthöhe von ca. $19 \mathrm{~cm}$ besitzen. Von letzterer entfallen ca. $16^{\mathrm{cm}}$ auf den Röhrchenkörper und ea. $3^{\mathrm{cm}}$ auf den Fuss. Die Röhrcheu werden, ehe man sie in Gebrauch nimmt, eine Stunde lang mit siedendem Wasser behandelt, da sonst später - besonders bei den leicht schmelzbaren Natronglassorten - Efflorescenzen an den Glasflächen auftreten, welche die Schönheit des Präparates beeinträchtigen würden. Hierauf lässt man die Röhrchen erkalten, mit destillirtem Wasser nachspülen und, verkehrt aufgestellt, vollkommen austrocknen. Nun werden

' Soyka und Král, Vorschläge und Anleitungen zur Anlegung von bacteriologischen Museen. (Aus dem hygienischen Institute der dentschen Universität in Prag.) Diese Zeitschrift. 1888. Bd.TV. S. 143.

Leitschr. t. Hygiene. v. 
sie wie gewöhnliche Reagensröhrchen mit Wattepfiopfen versehen, sterilisirt, mit Nährgelatine oder Nähragar beschickt, neuerdings im strömenden Dampfe oder discontinuirlich sterilisirt und, senkrecht aufgestellt - für Strichculturen im Koch'schen Blutserum-Erstanungs-Apparat schräg gelegt - erstarren gelassen. Impfung und Entwickelung bei Zimmertemperatur oder im Brütofen finden in bekannter Weise statt. Blutserum, Ascites-, Hydrocele- und Thoraxflüssigkeit werden sterilisirt in die sterilisirten Röhrchen eingefüllt und im Blutserum-Sterilisirungsapparat durch vier bis sechs 'Tage fractionirt nachsterilisirt und schliesslich, schräg gelegt, zum Trstarren gebracht.

Die meisten durchsichtigen Nährböden haben die bekannte unangenehme Eigenschaft, in Folge ausgepressten oder Condensationswassers an den Wandungen der Röhrchen mangelhaft zu adhäriren, wodurch diss missliche Abgleiten der schrïg erstarrten Masse statt hat. Dies verhütet man durch ein lïngeres Belassen der beschickten und sterilisirten Reagensröhrchen im Blutserum-Erstarrungsapparat nach stattgefundener Erstarrung. In ca. acht Tagen ist die oberste dünnste Partie so weit von ihrem überschüssigen $\mathrm{H}_{2} \mathrm{O}$-Gehalt befreit, dass ein Abgleiten nur mehr in sehr breiten Reagensröhren eintritt. Aus gleichem Grunde wurden auch engere als die gebrüuchlichen Reagensröhren gewählt.

Jene Culturen, welche sich derart typisch entwickelt haben, dass deren Conservirung wünschenswerth erscheint, werden in folgender Weise eingeschlossen.

Man erhitzt die obere Partie des Reagensröhrchens, etwa $4^{\mathrm{cm}}$ unterhalb des Glasrandes und $2^{\mathrm{cm}}$ unterhalb des Wattepfropfens (welcher nicht entfernt wird) in der Flatterflamme eines Kautschukgebläses oder eines Blastisches, vorerst in der nicht forcirten leuchtenden, dann in der forcirten nicht leuchtenden Flamme unter fortwährendem Drehen des Röhrchens so lange, bis die Flamme die röthlichgelbe Natriumfärbung zeigt, verwandelt durch entsprechendes Drehen des Gasregulirhahnes rasch die Flatterflamme in eine kleine Spitzflamme, vermittelst welcher eine scharf umschriebene Stelle des Röhrchenumfanges vollends erweicht bezw. weissglühend gemacht wird, und zieht nun ausserhalb der Flamme rasch auseinander, so dass das oberste Drittel der Röhre nunmehr durch eine Capillare mit dem übrigen Theile verbunden ist. Hierauf bricht man die Capillare in der Mitte $a b$ und zieht mit einer noch kleineren Spitzflamme den kleinen Kegel, welcher sich noch auf der Kuppe des Reagensröhrchens befindet, zur Gänze $a b$ und schmilzt unmittelbar darauf zu. Gewisse Handgriffe, welche das Einfallen des eben verschmolzenen Röhrchens oder das Auftreiben einer Blase oder gar ein Platzen der letzteren verhindern sollen, sind von einiger Wichtigkeit, wenn das Prïparat auch eine tech- 
nische Vollendung aufweisen soll. Eine Luftverdünmung war bereits im Beginn der Procedur durch das Vorwärmen mittelst Flatterflamme, dann durch stärkeres Erhitzen herbeigeführt worden. Während des Zuschmelzens ist demnach noch ein luftverdünnter Raum vorhanden, weshalb auch dic Kuppe sofort einsinkt, wenn nicht der äussere und innere Druck in's Gleichgewicht gebracht werden. Dies wird bewerkstelligt, wenn unmittelbar vor und nach dem Zuschmelzen der leere Theil des Reagensröhrchens ein oder einige Male rasch durch die Flamme gezogen wird. Nach dem Zuschmelzen lässt man die Kuppe durch die voll wirkende Flatterflamme verdicken und zieht im richtigen Momente, ehe sich eine Tendenz zum Linsinken bemerkbar macht, wieder den ungefüllten Theil durch die Flamme, bis die verdickte nunmehr abgeflachte Kuppe durch inneren Ueberdruck halbkugelförmig aufgeblasen erscheint. Bis zum erfolgten Abkühlen wird darauf noch einige Male durch die Flamme gezogen, um auch einem nachträglichen Einsinken vorzubeugen.

Alle diese Manipulationen müssen bei ununterbrochenem Drehen des Reagensröhrchens vorgenommen werden, weil sonst der Verschluss einseitig und unregelmässig ausfällt oder gar misslingt. Bei Agar, Blutserum, Ascites-, Hydrocele- und Thoraxflüssigkeit ist darauf zu achten, dass die Röhrchen möglichst wenig zur Ebene geneigt werden, um zu verhindern, dass die Cultur vom Condensationswasser benetzt und dadurch zum Abgleiten gebracht wird. Bei Bouillonculturen mit Häutchenbildung ist eine noch grüssere Vorsicht nöthig, um das charakteristische Häutchen nicht zu zerstören. Ein weiterer und wichtiger Grund, weshalb die Röhrchen möglichst wenig geneigt werden dürfen, wird später angeführt.

Ist das Zuschmelzen gut gelungen, so hat man nun Dauerpräparate von Stich- oder Strichculturen, wie sie die beiden Figg. 2 und 3 zeigen.

Um den Vegetationsverlauf im Impfstich der mikroskopischen Beobachtung zngänglich zu machen, dienen flache Reagensiöhrchen mit Glasfuss und mit möglichst parallelen Wandungen, wie eines hiervon in Fig. 4 auch im Querschnitt abgebildet ist.

Die Röhrchen haben ebenfalls eine Gesammthöhe von $19 \mathrm{~cm}$, wovon $16^{\mathrm{cm}}$ auf den Röhrchenkörper entfallen. Die Breite betrïgt etwas mehr als die übliche der runden Röhrchen, nämlich ea. $22 \mathrm{~mm}$, die Breite dagegen höchstens $6^{\mathrm{mm}}$ incl. Glaswandungen. Reinigung, Sterilisirung und Impfung wird in der bereits für die runden Rührchen geschilderten Weise vorgenommen. Zur Impfung bedient man sich einer langen und fein zugespitzten Nadel aus stärkerem Platindraht (ca. $0.65 \mathrm{~mm}$ D.), weil die Röhrchen so enge sind, dass man den Glasstab nicht mit einführen kann. Die Spitze der Platinnadel bietet ausserdem den Vortheil, dass das Nährsubstrat dem Eindringen derselben einen weit geringeren Widerstand 
entgegensetzt, als einem stumpfen Ende, weshalb auch ein Abweichen der Nadel von der intendirten Geraden nicht stattfindet und der Stich selbst. ein sauberes glattes Aussehen erhält.

Das Zuschmelzen der flachen Röhrchen bietet weniger Schwierigkeiten dar, als jenes der runden. Man verfährt anfang's wie bei den runden, sistirt aber das Drehen, wenn die Natriumflamme sichtbar zu werden beginnt. In diesem Stadium lässt man die betreffende Stelle der einen Schmalseite mittelst Spitzflamme weissglühend werden, wodurch die Glasmisse zum Fiusinken gebracht wird und eine concave Höhlung entsteht.
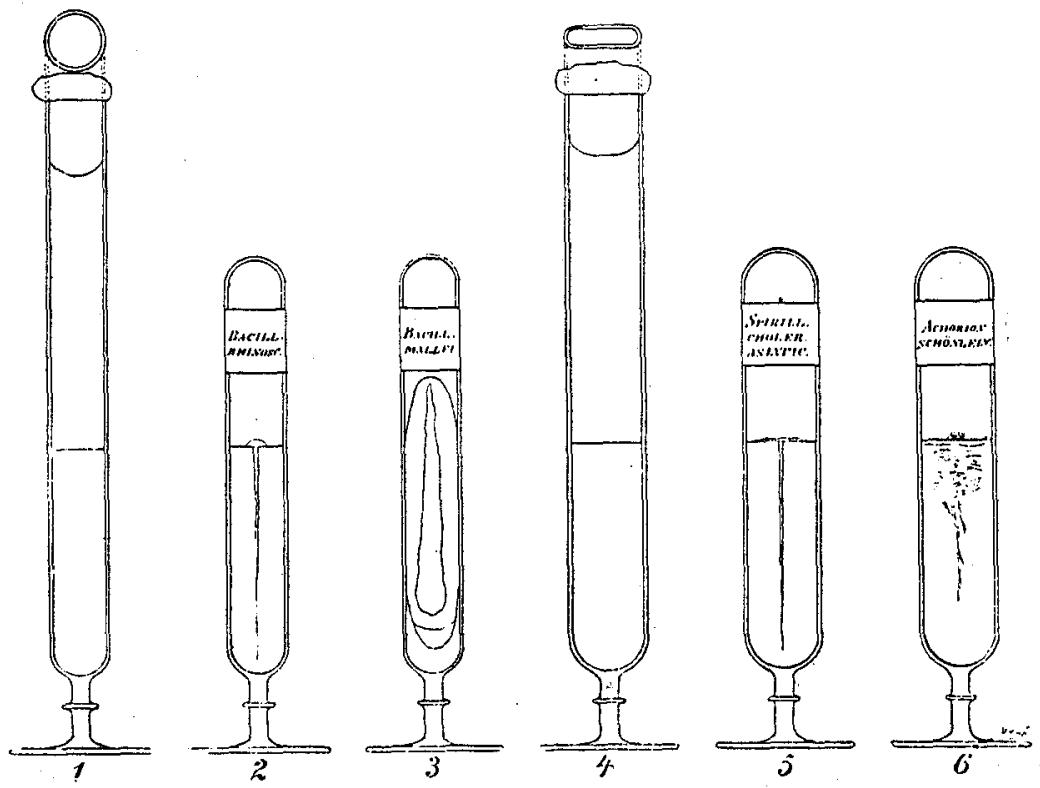

Dasselbe wird an der entgegengesetzten Seite vorgenommen und so setzt man, mit der vorangegangenen wieder beginnend, so linge abwechselnd fort, bis sich die Einsenkungen in der Witte berühren. The dieser Moment eingetreten ist, muss die Spannung in dem Röhrchen wieder nahe dem Atmosphärendrucke gebracht werden. Nun zieht man rasch ab und verfährt weiterhin, um eine schöne halbkreisförmige Kuppe zu erzielen und event. Finsinken oder übermässiges Aufblasen zu verhüten, wie bei den runden Röhrchen.

Die gelungenen Röhrehen besitzen die Gestalt der Figg. 5 und 6 .

Sehr hübsche Dauerpräparate erhält man auch von Kartoffelculturen in runden Reagensröhrchen.

Man bedient sich hierzu der runden Reagensröhrchen mit Glasfuss nuch Fig. 1, jedoch von erhehlich grüsserem Durchmesser, cil. 25 bis 
$26^{\mathrm{mm}}$. Die Kartoffeh werden in der üblichen Weise gereinigt, sterilisirt und gekocht, dann mittelst Kartoffelbohrer aus Messing, dessen innerer Durchmesser ca. $0.5^{\mathrm{mm}}$ weniger beträgt als der innere Durchmesser der Reagensröhrchen, in ci. 8 bis $9 \mathrm{~cm}$ lange Cylinder geschuitten und letztere mach der Methode Meade Bolton's ${ }^{1}$ (auch Globig ${ }^{2}$ bediente sich bei seinen Untersuchungen schräg geschnittener Kartoffelcylinder) mit dünnem Messer möglichst schräg in zwei Theilo getheilt. Die so erhaltenen SchnittHăchen bilden zugleich die Culturfüchen. Man bringt hierauf die, in der Form den schrïg erstarrten Nährböden ähnlichen, Kartoffelstücke in die Reagensröhren, versieht letatere mit Wattepfropfen und sterilisirt sie eine Stunde lang im strömenden Dampt. Die Aussaat erfolgt als Strich mittelst Nadel oder - von Bouillonculturen aus - mittelst sehr kleiner Oese. Dis Vorgehen und die Vorsichtsmaassregeln beim Einsehmelzen entsprechend entwickelter Culturen sind dieselben, wie bei den runden Reagensröhrchen nach Fig. 1.

Ehe man an das Einschmelzen schön entwickelter Culturen schreitet, ist es rathsam, sich die nöthige Uebung vorerst an gewöhnlichẹn ungrefüllten, später an gefüllten aber nicht geimpften Reagensröhrchen zu erwerben. Man möge, wie bereits erwähnt, insbesondere bei Culturen in flüssigen Nährmedien oder mit ausgepresstem und Condensationswasser auf die möglichst wenig geneigte Lage des Röhrchens acht haben; nicht allein deshalb, um die Cultur intact zu erhalten. Käme durch Unachtsamkeit ein Flüssigkeitstropfen mit einer erhitzten Stelle des Reagensröhrchens in Berührung, so würde eine kleine Explosion stattfinden und die umhergeschleuderten Glassplitter könnten unter Umständen eine Infection herbeiführen. Die Gelatineröhrchen sind während des Zuschmelzens bei dem gestauchten Ping des Glasfusses zu fassen, damit ein Verflüssigen des Inhaltes durch die Handwärme vermieden wird.

Selbstverständlich eignen sich zur Herstellung von . Reagensg]asDauerpräparaten ausser den bereits angeführten Nährmedien auch die meisten der bisher empfohlenen; beispielsweise der Neisser'sche ${ }^{3}$ Fucus Crispus-Nährboden, das Eieralbumin nach Schenk ${ }^{4}$ und Dal Pozzo, ${ }^{5}$

1 A method of preparing potatoes for bacterial cultures. Medical News. 1887. Vol. I. p. 318.

2 Ueber Bacterienwachsthum bei 50 bis $70^{\circ}$. Diese Zeitschrift. Bd. III. S. 294.

3 Kleine Beiträge zur bacterioskopischen Methodik. Centralblatt für Bacteriologie und Parasitenkunde. 1888. Bd. III. Nr.16. Sep.-Abdr.

4 Fester Nährboden zur Züchtung der Mikroorganismen. K. k. Gesellsch. der Aerzte in Wien. Sitzung rom 29. April 1887. Allgemeine Wiener med. Zeit. 1887. Bd. XXXIY. S. 214.

${ }^{5}$ Das Eiweiss der Kibitzeier als Nährboden für Mikroorganismen. Medicinische Jahrö̈̈cher. 1887. S. 523. 
die Raskin'schen" Milchpepton-, Milchcalseïn- und Milcheiweissnährböden u. a. $m$.

Hinige Aufmerksamkeit hat man der Bereitung der Nährböden zn sehenken, welche für Dauerpräparate bestimmt sind. Die Nährgelatine soll absolut farblos sein, was sich erzielen lässt, wenn nach erfolgtem Peptonzusatz kein langdauerndes Erhitzen mehr statt hat. Allerdings ist auch eine gelblich gefärbte Gelatine, insofern sie nur vollkommen klar ist und beim Aufkochen derselben keine Prïcipitate ausgefilllt werden, für Culturzwecke gut geeignet und ihr Nährwerth kann derselbe sein, wie jener einer farblosen. Man verzichtet jedoch bei Verwendung einer gelblichen Nährgelatine auf ein differenzial-diagnostisches Hülfsmittel.

Es haben nämlich ausser den bisher als solche bekannten, das Nährsubstrat verfärbenden Mikroorganismen auch noch andere dieselbe Eigenschaft, wenngleich in vermindertem Grade. Bei einer zu anderen Zwecken angestellten Versuchsreihe mit pathogenen und nicht pathogenen Mikroorganismen in den vorbeschriebenen flachen Reigensröhrchen wurden folgende Verfärbungen beobachtet.

Farblose Nährgelatine wird verfürbt durch:

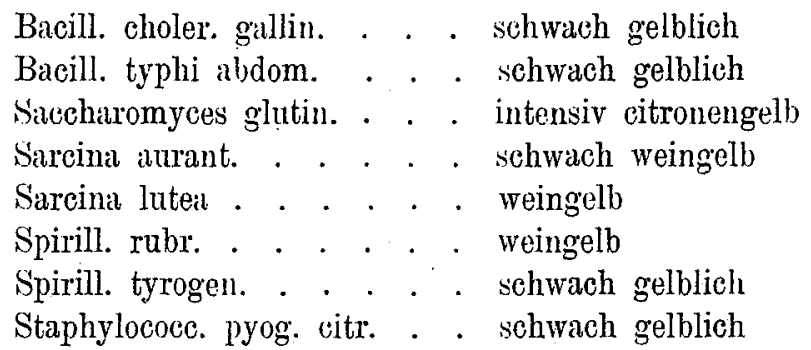

Das Nährsubstrat blieb unverändert bei:

Bacill. cavicida, diphther. colomb., Neapolit., Microc. trachom., Oïdium lactis, Protens vulgar., Spirill. Finkler et Prior, Staphyluc. pyog. alb. et aureus.

Bei diesem Versuche wurden alle Reagensröhrchen mit der gleichen Nährgelatine beschickt, allen Operationen zu gleicher Zeit und von gleicher Zeitdauer unterworfen, an demselben Tage geimpft, acht Tage nach der Impfung zugeschmolzen und nach vier Monaten gleichzeitig untersucht. Einige nicht geimpfté, sonst aber gleich behandelte Controlröhrchen dienten zur Gegenprobe. Bei den die Gelatine verflüssigenden Arten zeigten die Flüssigkeits- und die allenfalls zum Theile nicht verflüssigte Gelatinesäule

1 Zur Züchtung der pathogenen Mikroorganismen auf aus Milch bereiteten festen und durchsichtigen Nährböden. Petersburger medicin. Wochenschrift. 1887. Nr. 43 . 
die gleiche Verfärbung. Bei den nicht verfärbenden aber verflüssigenden blieb auch die Flüssigkeitssäule unverfärbt.

Betrachtet man ein "schwach gelblich" verfärbtes Gelatine-Röhrchen für sich allein, ohne Vergleichsobject, so fällt die Verfärbung nicht in's Auge, man würde sie eher der Bereitungsweise des Nährsubstrats zuschreiben. Mit einem der Controlröhrchen oder einem unverfärbten Präparat verglichen, ergiebt sich eine von Weitem erkennbare Differenz, welche nicht übersehen werden kann.

Inwiefern die Verfärbung farbloser Nährgelatine durch Mikroorganismen, welche als substratverfärbend bisher nicht bekannt sind, zur Differenzial-Diagnose geeignet ist, müsste durch eime grössere Zahl Versuchsreihen mit den bisher bekannten und in Nährgelatine züchtbaren Mikroorganismen festgestellt werden, wobei insbesondere der Zeitpunkt des Eintritts der Verfärbung, deren Intensität und die Umstände, unter welchen sie erfolgt, zu berücksichtigen wären.

Der Nähragar soll ebenfalls vollständig farblos und möglichst klar sein, damit die Stichcultur im flachen Röhrchen unter dem Mikroskope bequem untersucht werden könne. Man bereitet selben nach der von Schottelius ${ }^{1}$ modificirten Methode und vermeidet auch hier wieder ein langdauerndes Erhitzen nach stattgefundenem Peptonzusatz.

Die flachen Röhrchen können ihrer ganzen Länge nach mittelst schwacher Vergrösserung durchmustert werden. Die Vegetation ist nach einer Richtung im Raume beschränkt, sie kann sich dagegen nach der Breite hin unbehindert entwickeln. Dieses räumlich bedingte Wachsthum ist für die mikroskopische Beobachtung günstig, man erhält bei den meisten dieser Stichculturen ein scharf contourirtes Bild mit dissolvirten Details.

Eine mit 42 Mikroorganismen in 86 Hachen Agar-Röhrchen angestellte Versuchsreihe ergab mikroskopisch charakteristische Impfstiche bei den folgenden:

Bacill. butyr., cavicida, cuniculicida, erysip. porci, mallei, murisept., pneumon. Friedl. und rhinosclerom., Bact. lactis aërog., Jueuconost. mesenter., Microc. versicol., Proteus vulgar., Saccharom. glut., Sarcina lut., Spirill. chol. asiat. und tyrogen., Staphylococcus pyogen. aur. und Streptoc. pyog.

Ein weiterer Vortheil, welchen die flachen Röhrchen gewähren, besteht darin, dass sie die Anlegung von Stichculturen in thierischen und menschlichen Blutsera ermöglichen. Die erstarrte Serumschicht ist so

${ }^{1}$ Einige Neuerungen an bacteriologischen Apparaten. Centralblatt f. Bacteriologie und Parasitenkunde. 1887. Bd. II. S. 97, bezw. S. 100. 
dünı, dass sie - ein richtiges Eirstarrenlassen vorausgesetzt - nahezu vollkommen durchsichtig bleibt und eine genaue makroskopische und mikroskopische Beobachtung gestattet.

Die objective Darstellung des Impfstiches in flachen Röhrchen ist mittelst des sog. Scioptikons bis zu 100 mal Vergrösserung leicht und ohne Mühe oder besondere Vorbereitungen zu bewerkstelligen. Das Verfahren weicht von der Projicirungsweise anderer transparenter Gegenstände nicht $a b$, weshalb hier daranf nicht näher eingegangen wird.

Für Dauerpräparate anaërober Mikroorganismen sind zugeschmolzene Röhrchen gewissermassen prädestinirt. Die Anlage von Culturen facultativer Anaëroben durch Aufschichtung von Nührsubstrat über die Impfstelle, Abschluss durch sterilisirtes Oel u. s. w. ist bekannt. Die durch das Zuschmelzen des Röhrchens hervorgebrachte Luftverdünnung, welche durch vorheriges beliebig starkes Erhitzen des oberen leeren Theiles des Reagensröhrchens namhaft vergrössert werden kann, reicht für die unbehinderte Entwickelung vorerwähnter Mikroorganismen aus.

Bei obligaten Anaëroben, die nur unter völligem Ausschliessen des 0 gedeihen, verfährt man nach der einfachen Methode Carl Iränkel's, ${ }^{1}$ mit der Modification, dass man nach beendeter Entwickelung der Culturen das Gaszuleitungsrohr bis zur unteren Fläche des Gummipfropfeus emporzieht und ca. 2 bis $3^{\mathrm{cm}}$ unterhalb des letzteren das Zuschmelzen des Reagensröhrchens vornimmt. liür Rollculturen müssen die Röhrrchen (nach Fig. 1) einen grösseren Durchmesser besitzen, ca. $22^{\mathrm{mm}}$, und 5 bis $6^{\mathrm{cm}}$ unterhalb des Randes mit einer rings um die Peripherie laufenden Einschnürung versehen sein. Diese wallartige Verengerung des Röhrchens hindert die Ausbreitung des Nährsubstrats beim Rollen im oberen Theile des Röhrchens, welcher für das Zuschmelzen substratfrei bleiben muss.

Das Oeffnen eines eingeschmolzenen Dauerpräparates - wenn es aus irgend welchem Grunde wünschenswerth erscheint - lässt sich bewerkstelligen, ohnie Cultur oder Röhrchen gefährden, bezw. fernerem Gebrauche entziehen zu müssen. Man erwärmt vorsichtig unter ununterbrochenem Drehen und entsprechend geneigter Lage die Kuppe des Röhrchens in der leuchtenden Flamme, erhitzt darauf rasch in grosser Spitzflamme selbe bis zur Weissglühhitze, erwärmt nun sofort den der Kuppe zunächst gelegenen Theil des Röhrchens, worauf die erweichte Kuppe zu einer grossen Kugel aufgeblasen wird, welche auch meistens zum Platzen kommt. Die Kugel oder die Reste derselben werden vorsichtig entfernt und der verbliebene scharfe unregelmässige Rand in der Flatterflamme glatt ge-

1. Ueber die Cultur anaërober Mikroorganismen. Centralblatt für Bacteriologie und Parasitenlcunde. 1888. Bd.III. S. 763. 
schmolzen (wobei die Flamme nicht in die Oeffinung hineinspülen darf). Nun lässt man das Röhrehen, diesmal in so geneigter Lage, als es das ctwaige Condensationswasser gestattet, etwas erkalten und verschliesst es mit dem, einem leeren aber sterilisirten Reagensröhrchen entnommenen Wattepfropfen.

Die vorbeschriebenen Reagensiglas - Dauerpräparate sollen in erster Reihe ein stets bereites Demonstrationsmaterial bieten und das zeitraubende Erneuern der Culturen möglichst vermeiden lassen. In zweiter Reihe käme der gleichwerthige Vortheil, welchen Dauerpräparate der Forschung gewähren. Bei einigermassen intensiverer Arbeit ist es ohnehin nur unter Aufwand sehr vieler Mühe und Kostbarer Zeit müglich, eine sich stetig mehrende Reihe von Reinculturen der der bacteriologischen Analysis unterzogenen Fälle eine längere Zeit weiterzuführen, um Vergleichsmaterial für spätere Befunde zu besitzen. Mittel und disponible Zeit ziehen hierin oft enge Grenzen. Die Dauerpräparate sollen diese Grenzen möglichst weit herausrücken und es dem Forscher ermöglichen, mit geringen Mitteln jede seiner Reinculturen auf den gebräuchlichsten Nährsubstraten so zu conserviren, dass er noch nach Jahren die bacteriologischen Resultate eines gleichen oder ähnlichen Fulles mit den heute erhaltenen Culturen zu vergleichen im Stande ist. ${ }^{1}$

Prag, im October 1888.

${ }^{1}$ Die hier beschriebenen Röhrchen liefert die Firma Franz Batka in Prag, I, Bergstein 10. 